\title{
Oral tolerance is inefficient in neonatal mice due to a physiological vitamin A deficiency
}

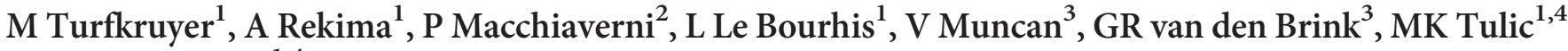 \\ and V Verhasselt ${ }^{1,4}$
}

Increased risk of allergy during early life indicates deficient immune regulation in this period of life. To date, the cause for inefficient neonatal immune regulation has never been elucidated. We aimed to define the ontogeny of oral tolerance and to identify necessary conditions specific for this stage of life. Ovalbumin (OVA) was administered orally to mice through breast milk and efficiency of systemic tolerance to OVA was assessed in adulthood using a model of allergic airway inflammation. Oral tolerance induction was fully efficient starting third week of life. Inefficiency in neonates was a consequence of abnormal antigen transfer across the gut barrier and retinaldehyde dehydrogenase expression by mesenteric lymph node $\mathrm{CD}_{103}{ }^{+}$neonatal dendritic cells, resulting in inefficient T-cell activation. Neonates' serum retinol levels were three times lower than in adult mice, and vitamin A supplementation was sufficient to rescue neonatal defects and allow tolerance induction from birth. The establishment of oral tolerance required the differentiation of Th1 lymphocytes in both vitamin A-supplemented neonates and 3-week-old unsupplemented mice. This knowledge should guide the design of interventions for allergy prevention that are adapted to the neonatal stage of life such as vitamin $\mathrm{A}$ supplementation.

\section{INTRODUCTION}

Oral immune tolerance represents a key feature of intestinal immunity, which will prevent gut inflammation and allergy. Importantly, gut-induced tolerance is also involved in systemic immune regulation and the induction of oral tolerance has been examined as a therapeutic strategy in the treatment of immunemediated diseases, such as autoimmune encephalitis, type 1 diabetes, and allergy. ${ }^{1}$ Mechanisms of oral tolerance have been the focus of extensive research in mouse models and these studies identified the following four crucial steps for efficient development: (1) a controlled antigen transfer across the small intestinal epithelial barrier, (2) antigen presentation in the mesenteric lymph node (MLN) by CD103-positive dendritic cells (DCs), (3) the expansion of lymphocytes with regulatory properties (Tregs), and (4) homing of these Tregs toward tissues where they will prevent disease. ${ }^{2}$

Although first exposure to an oral antigen occurs physiologically early after birth (or even in utero), mechanisms of induction of oral tolerance have essentially been studied in adult mice and only a few studies assessed the efficiency of oral tolerance induction in early life. We have demonstrated that, in contrast to the adult where the sole administration of an antigen is sufficient for tolerance induction, maternal milk co-factors, such as transforming growth factor- $\beta$ or immunoglobulin $G$ (IgG), are required to induce tolerance to antigen administered during the whole breastfeeding period (i.e., first 3 postnatal weeks in the mouse). ${ }^{3,4}$ In addition, during the neonatal period (i.e., first week in mice), mice were shown to be refractory to oral tolerance induction through breast milk $^{5}$ and even primed upon direct soluble antigen oral antigen administration, ${ }^{5-9}$ and the mechanisms underlying this defect remained unknown. ${ }^{5-9}$ A high susceptibility to allergic disease in infants ${ }^{10,11}$ also indicates that the capacity to generate regulatory immune responses toward dietary antigens is reduced in early life in humans. Moreover, epidemiological studies showed that there is an optimal time window of 4-6 months for oral antigen exposure and prevention of allergic and celiac disease. ${ }^{12,13}$ This indicates the need to understand which factor may prevent oral

\footnotetext{
${ }^{1}$ University of Nice Sophia Antipolis, TIM, EA 6302, Nice, France. ${ }^{2}$ Institute of Biomedical Sciences-University of São Paulo, São Paulo, Brazil. ${ }^{3}$ Tytgat Institute for Liver and Intestinal Research and Department of Gastroenterology and Hepatology, Academic medical center, Amsterdam, The Netherlands and ${ }^{4}$ International Inflammation Network (in-FLAME) of the World Universities Network, Perth, Australia. Correspondence: V Verhasselt (verhasselt@unice.fr) 
tolerance induction in earlier life and to identify mechanisms for efficient oral tolerance induction to improve strategies of allergic disease prevention.

Non-communicable diseases such as inflammatory bowel disease, autoimmune, and allergic disease have become a major disease burden in both poorly and well-developed countries ${ }^{14}$ and there is accumulating evidence from epidemiological studies that early life immune dysregulation has an important role in their development. ${ }^{14}$ This is clearly a window of opportunity that needs to be understood for future prevention of disease. Accordingly, it is critical to elucidate the mechanisms underlying the ontogeny of efficient oral tolerance induction as a key mechanism for long-term immune homeostasis. Here we assessed the ontogeny of oral tolerance induction in a mouse model of allergic airway disease prevention and we uncovered the factors that are required specifically in this period of life for its efficient establishment.

\section{RESULTS}

\section{Oral tolerance is deficient in neonates}

We exposed mice orally to soluble ovalbumin (OVA) through maternal milk during the first, second, or third week of life; control mice received normal maternal milk only. The efficiency of oral tolerance induction on the systemic immune response to OVA was subsequently assessed at 6-8 weeks of age in a model of allergic airway inflammation to OVA. ${ }^{3,4}$ Oral administration of OVA to pups during the third week of life resulted in profound inhibition of eosinophilic airway inflammation (Figure 1a), serum OVA-specific IgE levels (Figure 1b), and lung interleukin (IL)-13 secretion (Figure 1c) compared with mice that did not receive OVA. This protection was comparable to the extent of tolerance we have previously observed upon OVA administration during the whole lactation period (Figure 1 and refs 3,4), indicating that exposure at the end of the neonatal period is sufficient to establish oral tolerance. In contrast, OVA-induced allergic airway inflammation was only partially prevented in mice when OVA was given during their second week of life, whereas no prevention was observed at all if neonatal mice were exposed in the first week only (Figure 1). We verified whether difference in OVA milk content may explain this observation and found similar levels of OVA in milk from mothers exposed during their first or third week of lactation (156 \pm 17 and $157 \pm 54 \mathrm{ng} \mathrm{ml}^{-1}$, week 1 and week 3 , respectively, mean \pm s.e.m., $n=5$ and 4). These observations demonstrate an intrinsic inability of neonates to establish oral tolerance at birth and that mechanisms responsible for oral tolerance have to be acquired in the first 3 weeks of life.

\section{Abnormal antigen transfer and permeability in neonatal small intestine}

Evidence in the adult indicates that a tight control of antigen transfer across the small intestinal epithelial barrier is a key step in the induction of oral tolerance. We therefore assessed whether the defect of oral tolerance in neonates was associated with abnormal trans-cellular antigen transfer across the small intestinal epithelium. Trans-cellular transfer of intact horseradish peroxidase (HRP) across jejunal tissues from 4- to 17-dayold mice was examined ex vivo using Ussing chambers and in vivo by direct oral administration of HRP to pups and measuring the sera HRP levels. Permeability to HRP was markedly increased in neonates compared with 3-week-old mice both in vitro (Figure 2a) and in vivo (Figure 2c). We also assessed paracellular permeability using fluorescein sulfonic acid and found a similar increase in 1-week-old mice compared with 3-week-old mice (Figure 2b). These data confirm, in a physiological setting, the strong association found in adult between selective gut permeability and gut immune homeostasis. ${ }^{15,16}$

\section{Deficient antigen presentation by mesenteric lymph node cells and selective decrease in $\mathrm{CD}_{103}{ }^{+}$dendritic cells expressing retinaldehyde dehydrogenase activity}

It has previously been established that the development of oral tolerance is strictly dependent on cells residing in the MLN. ${ }^{2}$ We therefore assessed whether MLN cells from neonates were capable to present OVA to adult naive OVA-specific KJ1.26 $\mathrm{CD} 4{ }^{+}$lymphocytes purified from DO11.10 Rag $-/-$mice. We found that proliferation of OVA-specific $\mathrm{CD} 4{ }^{+}$lymphocytes stimulated by MLN cells derived from 1-week-old mice was $60 \%$ reduced compared with cells stimulated by the same a

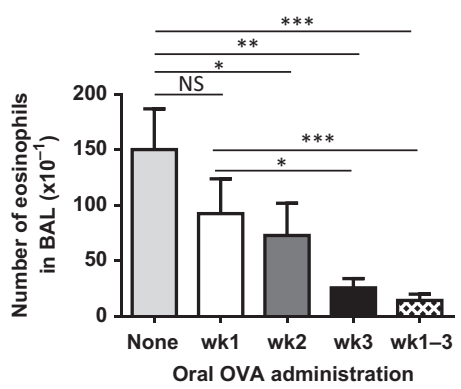

b

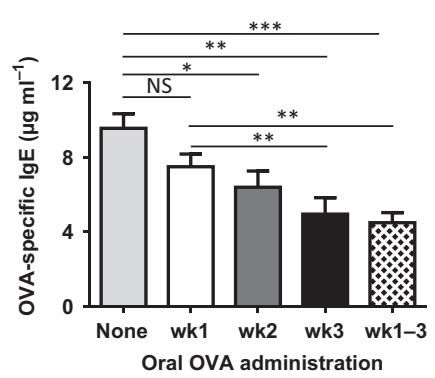

C

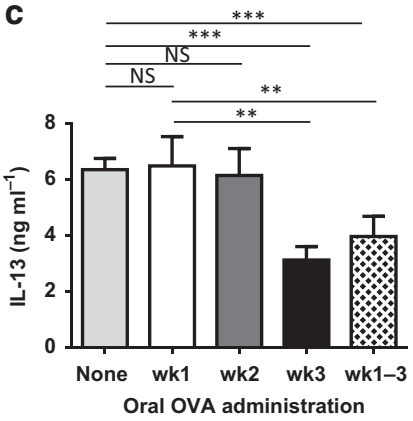

Figure 1 Ontogeny of oral tolerance induction. (a-c) OVA was given orally in early life during first (wk1), second (wk2), third (wk3), or during the 3 weeks of breastfeeding (wk1-3). Allergic airway inflammation was assessed in adulthood after IP immunization with OVA in alum followed by OVA respiratory challenges. Number of eosinophils in bronchoalveolar lavage (BAL) (a), serum levels of OVA-specific IgE (b), and IL-13 cytokine secretion by lung cells (c) are shown. Data are expressed as mean \pm s.e.m. of two experiments with $n=6-8$ mice per group in each experiment ${ }^{* *} P<0.01 ;{ }^{*} P<0.05$; NS $P>0.05$. IL-13, interleukin-13; IP, immunoprecipitation; NS, not significant; OVA, ovalbumin; wk, weeks. 

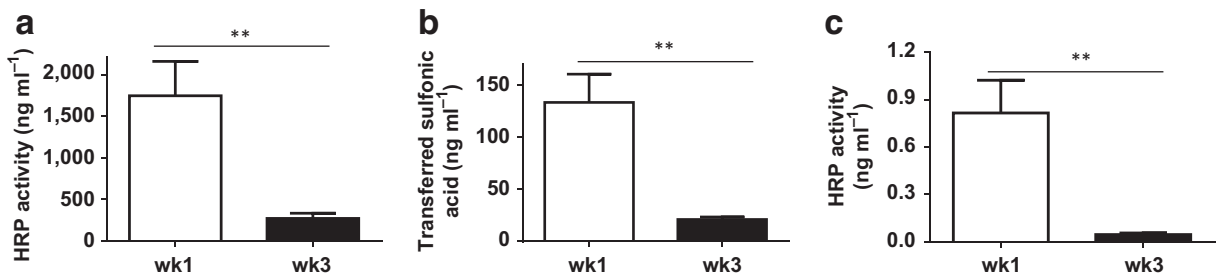

Figure 2 Increased trans-cellular and para-cellular gut permeability in neonatal period. Trans-cellular (a) and para-cellular (b) gut permeability were assessed ex vivo in 4-day (wk1)- and 17-day (wk3)-old mice by measuring intact HRP and fluorescein sulfonic acid transfer, respectively, across jejunum tissues in Ussing chamber after 150 min. Trans-cellular permeability to HRP was also measured in vivo after direct oral HRP administration to pups and measurement of sera HRP after $4 \mathrm{~h}$ (c). Data are expressed as mean \pm s.e.m. of three (a), one (b), and two experiments (c) with $n=6-8$ mice per group in each experiment. ${ }^{\star \star} P<0.01$. HRP, horseradish peroxidise; NS, not significant; wk, weeks.

number of MLN cells from 3-week-old mice (Figure 3a,b). To further assess whether neonates displayed in vivo deficient antigen presentation capacity upon oral antigen administration, we injected 1-day-old mice with OVAspecific $\mathrm{CD}^{+} \mathrm{T}$ lymphocytes and we evaluated their expansion in MLN from mice that received OVA during their first or third week of life. As shown in Figure 3c, we found significant OVA-specific $\mathrm{CD} 4{ }^{+} \mathrm{T}$ lymphocytes expansion in mice that received OVA during their third week, compared with mice that did not receive OVA. This expansion did not occur in mice that received OVA during their first week.

Among MLN cells, DCs are key players for naive T-cell activation and low DC frequency in the neonatal spleen has been described as a causal factor for defective antigenpresenting cell function in the neonate. ${ }^{17}$ In contrast, our analysis of the proportion of $\mathrm{MHCII}^{+} \mathrm{CD}_{11 \mathrm{c}^{+}} \mathrm{DC}$ among MLN cells revealed no difference between the different ages (Figure 3d,e); as expected, there was a significant increase in their absolute number from birth to week 3 (Supplementary Figure S1 online), reflecting total MLN cell number increase with age. The ability of MLN CD103 ${ }^{+} \mathrm{MHCII}^{+} \mathrm{CD} 11 \mathrm{c}^{+} \mathrm{DC}$ to metabolize vitamin $\mathrm{A}$ into retinoic acid as a result of retinaldehyde dehydrogenase (RALDH) expression has a critical role in the initiation and regulation of mucosal adaptive immune response. ${ }^{18,19}$ We therefore analyzed the representation of $\mathrm{CD}_{103}{ }^{+}$DC in MLN cells; similarly to total $\mathrm{DC}$, we found an equal representation of $\mathrm{CD} 103^{+} \mathrm{DC}$ between 1- and 3-week-old mice (Figure 3d,f), whereas absolute numbers were increasing with age (Supplementary Figure S1). However, when we assessed the capacity of $\mathrm{CD} 103^{+} \mathrm{DC}$ to metabolize retinol into retinoic acid, we found that the number (Supplementary Figure S1) as well as the frequency of CD103 ${ }^{+} \mathrm{RALDH}^{+}$MLN DC were significantly lower in 1-week-old compared with 3-week-old pups (Figure 3g,h). Thus, 1-week-old newborn mice have a specific deficiency of RALDH expressing $\mathrm{CD}_{103}{ }^{+} \mathrm{DC}$ that is associated with a reduced ability for antigen specific T-cell activation.

\section{A physiological neonatal vitamin A deficiency is responsible for low RALDH expression and T-cell expansion by $\mathrm{CD}_{103}{ }^{+} \mathrm{DC}$}

We next examined which factor may be responsible for low expression of $\mathrm{RALDH}$ in $\mathrm{CD}_{103}{ }^{+}$neonatal MLN DC.
Prolonged vitamin A-deficient diet is associated with low serum retinol levels ${ }^{20}$ and low RALDH expression in $\mathrm{CD}_{103}{ }^{+}$ MLN DC. ${ }^{21,22}$ We therefore measured the retinol concentration in serum of 1- and 3-week-old pups breastfed by mothers receiving a diet containing standard vitamin A levels. We found that the level of retinol in 1-week-old neonates was threefold lower than in 3-week-old mice (Figure 4a) and were comparable to the levels found in adult mice fed vitamin A-deficient diet for a prolonged period of time. ${ }^{20}$ We next set up to determine whether there was a causal relation between low neonatal retinol levels and low RALDH expression in neonatal MLN CD $103^{+}$DCs and deficient ability of neonatal MLN cells to stimulate $\mathrm{T}$-cell expansion in vitro. We supplemented lactating mice with vitamin $\mathrm{A}$-enriched $\operatorname{diet}^{20,23}$ to increase the retinol serum concentration in newborn mice. This approach successfully augmented neonatal retinol levels to the levels found in 3-week-old pups breastfed by mothers with a normal diet (Figure 4a). In vitamin A-supplemented neonates, the percentage of MLN CD103 ${ }^{+}$DC displaying RALDH activity reached the same value as 3 -week-old mice (Figure $4 \mathbf{b}, \mathbf{c}$ ). We further assessed whether vitamin A supplementation was sufficient to allow neonatal efficient antigen presentation. We found an increased capacity of MLN cells from vitamin A-supplemented neonates to stimulate OVA-specific T-cell proliferation to a level comparable to MLN cells isolated from 3-week-old mice on a regular diet (Figure 4d). The role of RALDH expression in the increased antigen presentation capacity of MLN cells from vitamin A-supplemented 1-weekold neonates was confirmed by the addition of the RALDH inhibitor LE135, which completely abolished the enhanced proliferation by MLN cells from neonates supplemented with vitamin A (Figure 4d). Proliferation by MLN cells from 3week-old mice under regular diet was also critically dependent on RALDH activity (Figure 4d). In agreement with these in vitro data, we found in vivo that oral OVA administration to vitamin A-supplemented neonates induced a similar OVAspecific T-cell expansion as the one observed in 3-week-old mice (Figure 4e).

We next asked whether the improved antigen presentation of $\mathrm{CD} 103^{+} \mathrm{DC}$ from vitamin A-supplemented neonates was solely due to increased retinoic acid secretion and/or was also dependent on additional mechanisms. MHCII and co-stimulatory molecules expression on DC are essential for naive 

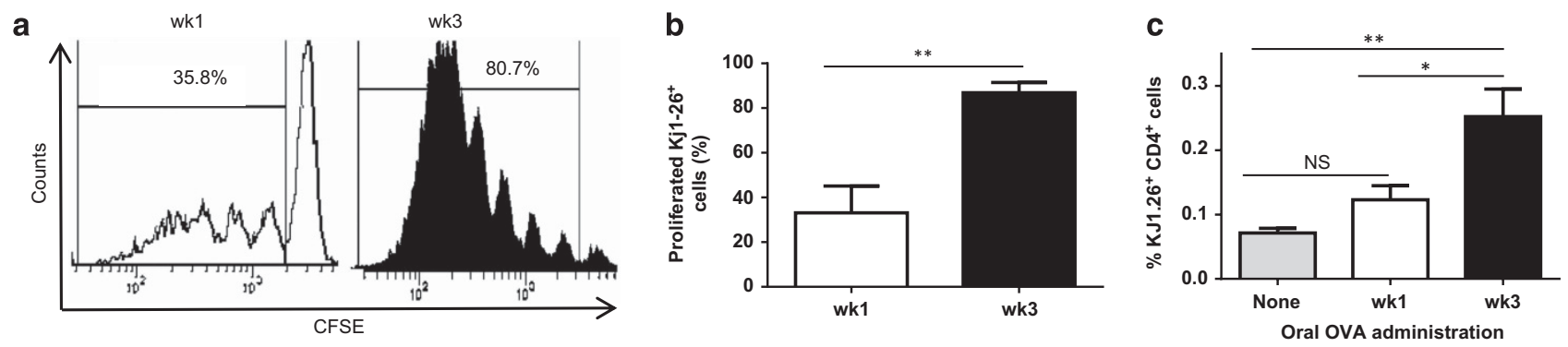

d

DC

$\mathrm{CD} 103^{+} \mathrm{DC}$
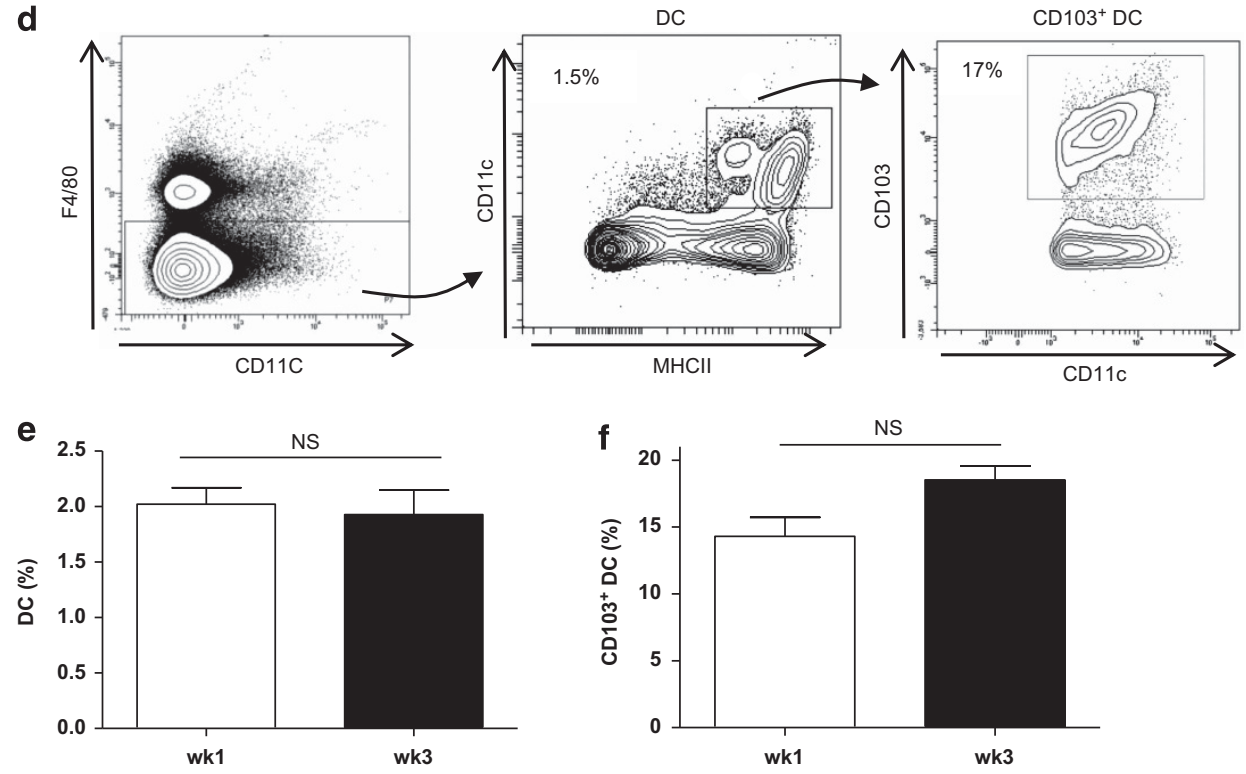

g

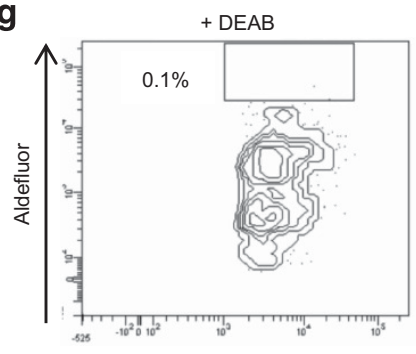

wk1

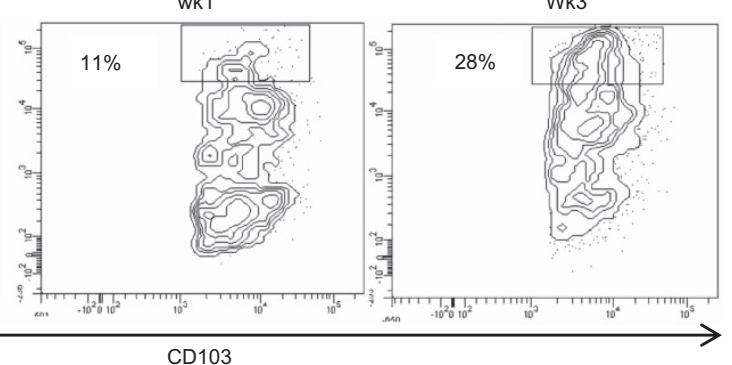

h

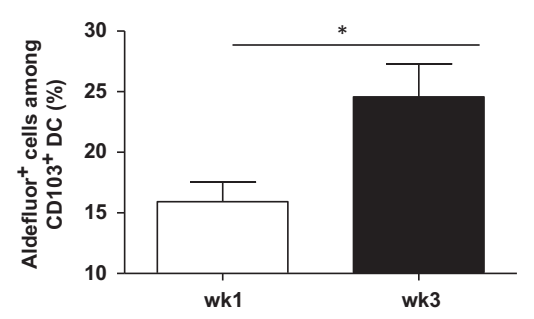

Figure 3 Defective antigen-presenting cell function and RALDH activity in neonatal MLN CD103 ${ }^{+}$DC. (a, b) OVA-specific CFSE-labeled Kj1-26 + $\mathrm{CD}^{+}{ }^{+} \mathrm{T}$ cells from adult mice were cultured with MLN cells from 4-day (wk1)- and 17-day (wk3)-old mice in the presence of OVA. After 4 days, T-cell proliferation was assessed by analysis of CFSE dilution by flow cytometry. (c) OVA-specific Kj1-26 + CD4 ${ }^{+}$T cells were injected IV in 1-day-old mice and their frequency among CD4 ${ }^{+}$T cells was assessed in 4-week-old mice that did not receive OVA (none) or received OVA during their first week (wk1) or their third week (wk3). (d-h) The proportion of DC was assessed in MLN cells from 4 and 17 days; (d) DC-gating strategy, (e) percentage of MHCII + $\mathrm{CD}_{11 \mathrm{c}^{+}}$cells (DC) among total MLN cells, (f) percentage of $\mathrm{CD} 103^{+}$cells among MLN MHCII $+\mathrm{CD} 11 \mathrm{c}^{+} \mathrm{DC} ;(\mathbf{g}, \mathbf{h})$ percentage of MHCII $+\mathrm{CD} 103^{+}$ $\mathrm{CD}_{11 \mathrm{c}^{+}} \mathrm{DC}$ displaying RALDH activity assessed using fluorescent Aldefluor ALDH substrate. A specific inhibitor of ALDH, diethylaminobenzaldehyde (DEAB), was used as negative control for background fluorescence. Data are expressed as mean \pm s.e.m. of five (b), one (c), or three (e-h) experiments with $n=6-8$ mice per group in each experiment. Representative dot plots are shown in $\mathbf{a}$, $\mathbf{d}$ and $\mathbf{g} .{ }^{*} P<0.01 ;{ }^{*} P<0.05$; NS $P>0.05$. CFSE, carboxyfluorescein succinimidyl ester; DC, dendritic cell; MLN, mesenteric lymph node; RALDH, retinaldehyde dehydrogenase; NS, not significant; OVA, ovalbumin; wk, weeks.

lymphocytes activation and MHCII and CD86 were shown to be increased in vitro on human blood derived DC by retinoids. $^{24}$ However, expression of MHC and CD86 was similar on MLN CD103 ${ }^{+}$DC from neonates regardless of their vitamin A supplementation (Supplementary Figure S2). We further assessed expression of other co-stimulatory (CD80) and co-inhibitory (PDL-1 and PDL-2) molecules on DC and found that their expression did not differ significantly in neonates supplemented or not in vitamin A (Supplementary Figure S2). As difference in expression of molecules involved in antigen presentation and in T-cell co-stimulation by $\mathrm{CD} 103^{+}$ DC from neonates supplemented or not with vitamin A, could not explain difference in their capacity of T-cell stimulation, we then assessed the capacity of neonatal $\mathrm{MLN} \mathrm{CD103}{ }^{+} \mathrm{DC}$ to 

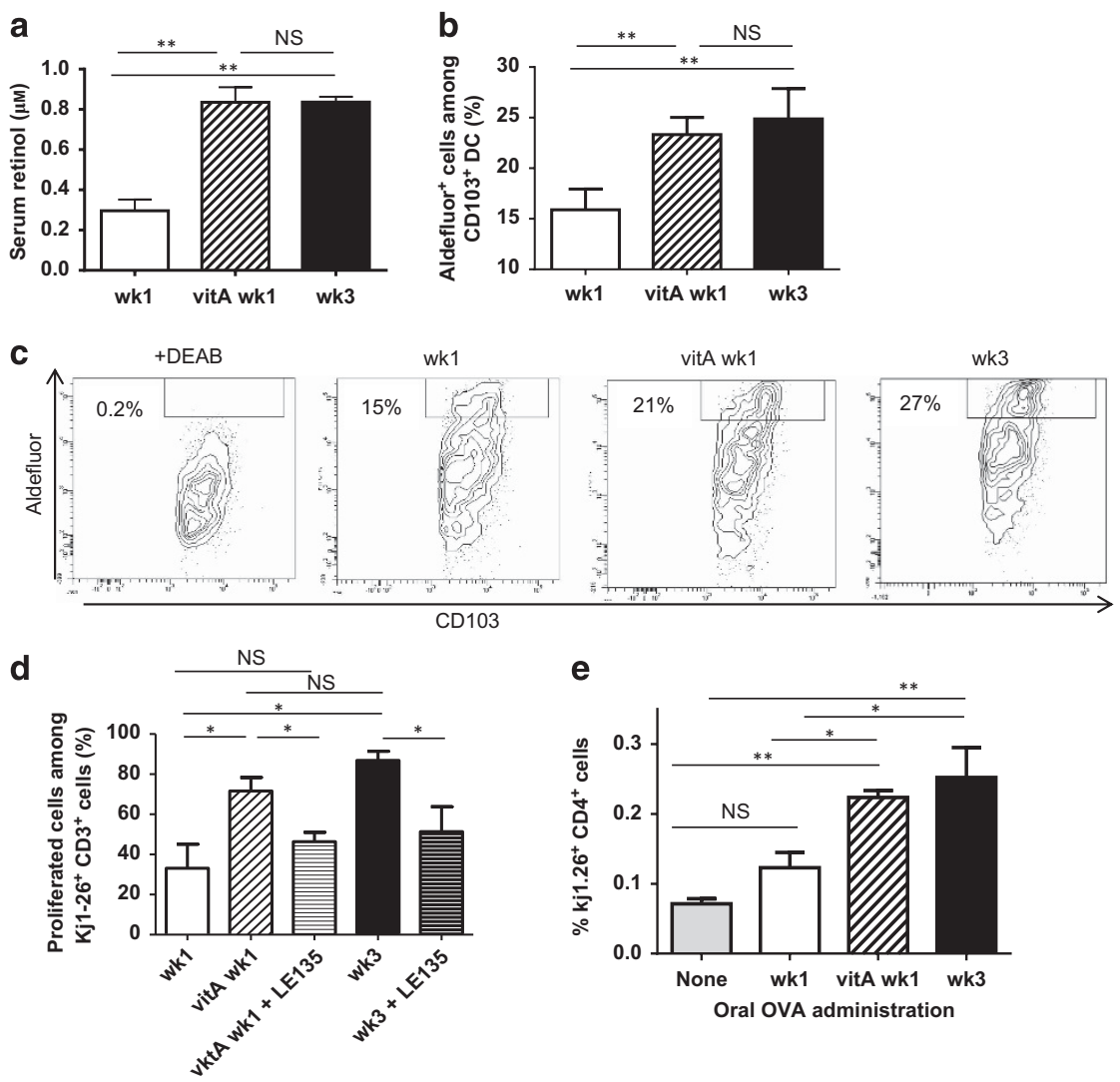

Figure 4 Vitamin A supplementation increases neonatal serum retinol levels, RALDH expression, and T-cell expansion. (a) Serum retinol levels and (b, c) RALDH $+\mathrm{CD}_{103^{+}}$MLN DC frequency were determined. (d) Proliferation of OVA-specific CFSE-labeled Kj1-26 + CD4 ${ }^{+}$T cells cultured with OVA and with MLN cells from 4-day-old mice with (Vit A wk1) or without (wk1) vitamin A supplementation and 17-day-old mice (wk3) in the presence of OVA. Where indicated, LE135 RALDH inhibitor was added to culture of MLN cells. (e) OVA-specific Kj1 - $26+$ CD4 ${ }^{+}$T cells were injected IV in 1-day-old mice and their frequency among $\mathrm{CD} 4^{+} \mathrm{T}$ cells was assessed in 4-week-old mice that did not receive OVA (none) or received OVA during their first week with (Vit A wk1) or without (wk1) vit A supplementation or their 3rd week (wk3). Data are expressed as mean \pm s.e.m of values obtained in six mice in each experimental group (a) and mean \pm s.e.m of five $(\mathbf{b}, \mathbf{d})$ or one $(\mathbf{e})$ experiments with $n=6-8$ mice per group in each experiment. Representative dot plots are shown in $\mathbf{c} ;{ }^{* *} P<0.01$; ${ }^{*} P<0.05$; NS $P>0.05$. CSFE, carboxyfluorescein succinimidyl ester; DC, dendritic cell; IV, intravenous; MLN, mesenteric lymph node; NS, not significant; OVA, ovalbumin; wk, weeks.

capture OVA as a necessary and limiting step for antigen presentation. ${ }^{25}$ In vitro, we found that MLN CD103 ${ }^{+}$DC derived from 1-week-old mice had a twofold lower capacity to capture OVA as compared with DC from 3-week-old mice, whereas vitamin A supplementation rescued neonatal antigen capture capacity in 1-week-old pups (Supplementary Figure S3a). However, these data were not confirmed in vivo as we found a similar uptake of orally directly administered fluorescent OVA in $\mathrm{CD} 103^{+}$MLN DC from 1-week-old mice supplemented or not with vitamin A and from 3-week-old mice (Supplementary Figure S3b). Altogether, these data indicate that the lack of retinoic secretion by MLN CD $103^{+} \mathrm{DC}$ is most probably the key causal factor for defect in antigen specific T-cell activation by neonatal DC.

\section{Neonatal gut barrier dysfunction is corrected by vitamin A} supplementation

Vitamin A not only has an important role in the regulation of intestinal mucosal immunity but also affects intestinal epithelial homeostasis. ${ }^{26}$ We next wondered whether vitamin A could correct the increased antigen transfer across the 1-week-old neonatal epithelial barrier (Figure 2). We found that vitamin A supplementation in neonates decreased HRP trans-cellular permeability in both ex vivo and in vivo experimental settings (Figure 5a,c). Similarly, para-cellular permeability to sulfonic acid was reduced by vitamin A supplementation (Figure 5b). Both trans- and para-cellular permeability reached levels comparable to those observed in 3-week-old mice (Figure 5a-c). We further assessed whether vitamin A supplementation was sufficient to stimulate other parameters of neonatal gut maturation. ${ }^{27,28}$ The intestinal epithelium of newborn mice lacks crypts, which only develop in the first 3 weeks of life. We therefore measured crypt length in jejunal tissues from 1-week-old control and vitamin A-supplemented neonates and from 3-week-old pups on a regular diet. This showed that vitamin A supplementation accelerated crypt development in 1-week-old mice as crypt depth in vitamin A-supplemented mice was comparable to that normally observed in 3-week-old mice (Figure 5d). We further examined whether vitamin A supplementation affected the expression of Blimp-1, a transcription factor that is specifically expressed in the neonatal intestinal epithelium and delays 

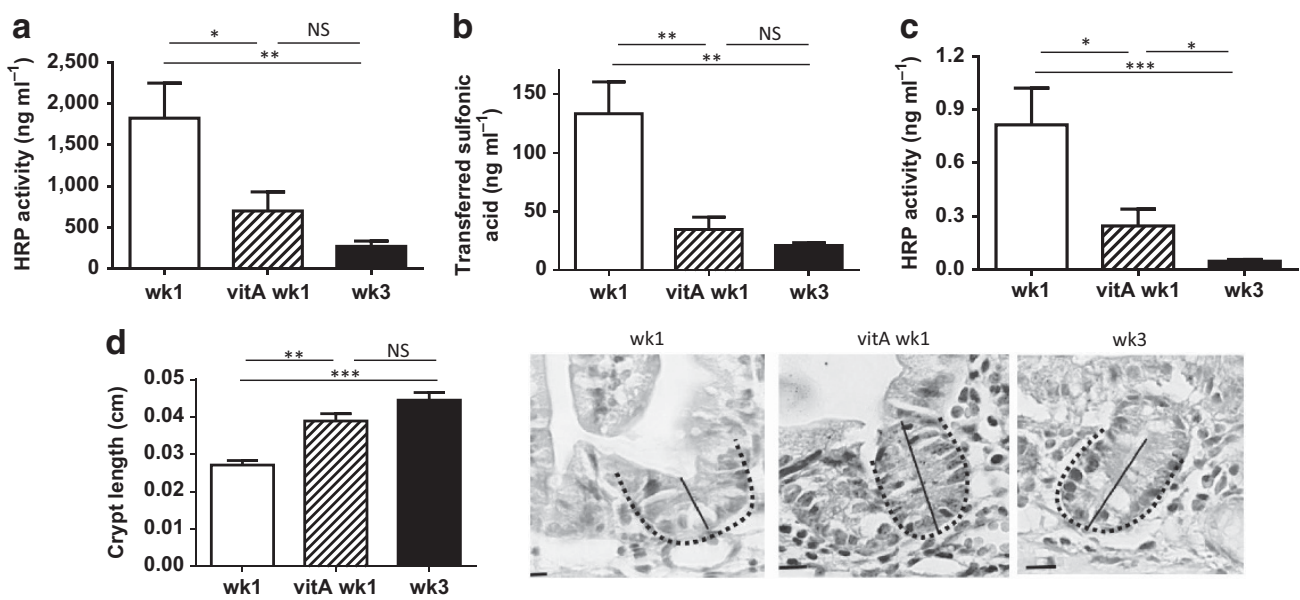

Figure 5 Vitamin A supplementation stimulates neonatal gut maturation. Trans-cellular (a) and para-cellular (b) gut permeability assessed by measuring intact HRP and fluorescein sulfonic acid transfer, respectively, across jejunum tissues in Ussing chamber after 150 min. Trans-cellular permeability to HRP was also measured in vivo after oral HRP administration to pups (c). (d) Histologic measurement of crypt length. Data are expressed as mean \pm s.e.m. of three $(\mathbf{a})$, two $(\mathbf{b}, \mathbf{c})$, one $(\mathbf{d})$ experiments with $n=6-8$ mice per group in each experiment. ${ }^{* * *} P<0.005,{ }^{* *} P<0.01 ;{ }^{\star} P<0.05 ;$ NS $P>0.05$. HRP, horseradish peroxidise; NS, not significant; wk, weeks.
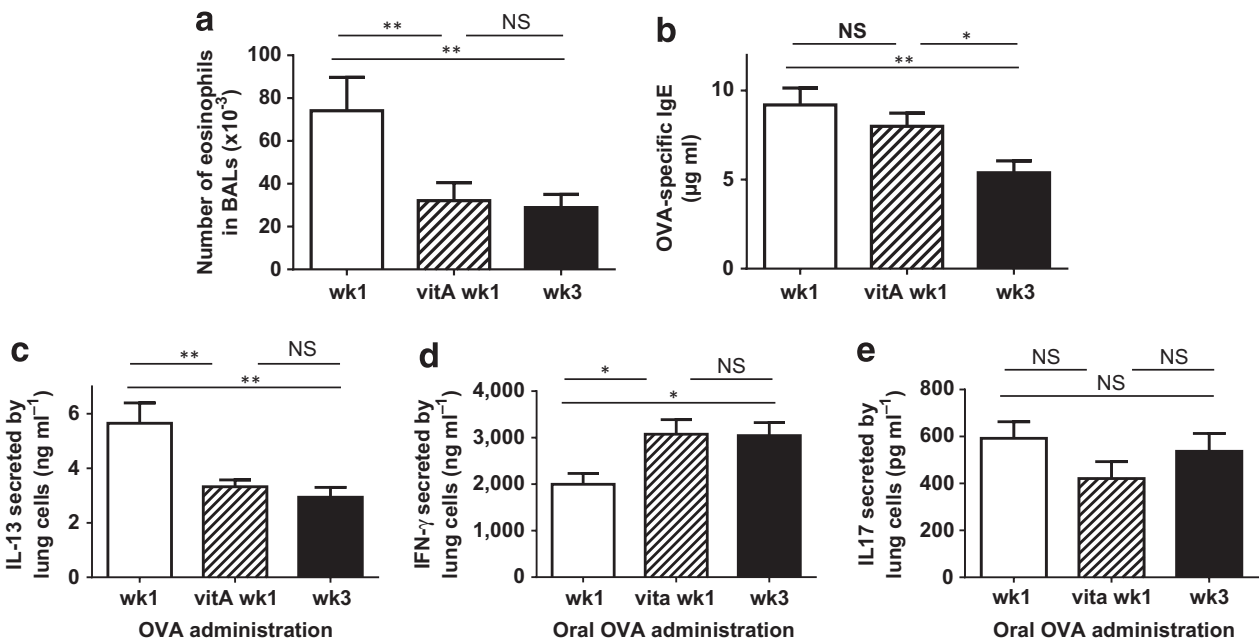

Figure 6 Vitamin A supplementation allows oral tolerance induction from birth. OVA was given orally at the indicted time windows and allergic airway disease was assessed in adulthood. Number of eosinophils in bronchoalveolar lavage (BAL) (a), serum levels of OVA-specific IgE (b) and IL-13 (c), IFN- $\gamma$ (d), and IL-17 (e) cytokine secretion by lung cells. Data are expressed as mean \pm s.e.m. of two experiments with $n=6-8$ mice per group in each experiment. ${ }^{* \star} P<0.001$, ${ }^{\star \star} P<0.01$; ${ }^{\star} P<0.05$; NS $P>0.05$. IFN- $\gamma$, interferon-gamma; IL, interleukin; NS, not significant; OVA, ovalbumin; wk, weeks.

epithelial maturation; ${ }^{27,28}$ we found no impact on its expression in neonatal gut (Supplementary Figure S4). Similarly, vitamin A supplementation did not induce premature expression of enzymes that are specifically expressed on adult type epithelium such as sucrose isomaltase (Supplementary Figure S4). This indicates that although vitamin A supplementation accelerated crypt formation and barrier integrity, it had no major impact on other aspects of epithelial maturation linked to its enzymatic activity.

\section{Vitamin A supplementation is sufficient to allow IFN- $\gamma$-driven oral tolerance induction from birth}

Having demonstrated that vitamin A supplementation makes antigen transfer across the epithelial barrier and subsequent presentation by MLN cells in 1-week-old mice comparable to 3-week-old mice, we next assessed whether it would also allow oral tolerance induction in the first week of life and prevention of allergy in adulthood. Oral OVA administration during the first week of life to mice with vitamin A supplementation inhibited eosinophilic airway inflammation and lung IL-13 secretion to the same extend as when OVA had been administered during the third postnatal week (Figure 6a,c). Inhibition of allergic airway inflammation in mice that had received OVA during their first week together with vitamin A supplementation or during their third week was associated with increased lung interferon-gamma (IFN- $\gamma$ ) secretion (Figure 6d) and unaffected IL-17 secretion (Figure 6e). Although IgE were found to be decreased in 
mice that received OVA during their week, they were not affected in mice that had received OVA and vitamin A during their first week (Figure $\mathbf{6 b}$ ). IgA and IgG2a were not affected neither in this condition (Supplementary Figure S4).

In order to determine whether maternal metabolism of vitamin A was necessary to allow oral tolerance induction in neonates, we administered vitamin A supplement directly to the pups. Our preliminary data indicated that this approach was sufficient to increase RALDH expression in $\mathrm{CD}_{103}{ }^{+}$MLN $\mathrm{DC}$ and to induce allergic airway inflammation prevention by oral antigen administration in neonates (Supplementary Figure S5).

We next sought to determine by which mechanisms vitamin A supplementation in neonates allowed prevention of allergy in adulthood. A significant body of evidence suggests a role for Foxp3-expressing Tregs as mediators of oral tolerance in adult mice $^{2}$ and several in vitro studies have clearly established that MLN CD103 ${ }^{+} \mathrm{RALDH}^{+}$DCs stimulate induction of Foxp3 Treg by conversion of vitamin A into retinoic acid. ${ }^{18,19} \mathrm{We}$ therefore assessed both in vitro and in vivo conditions of oral tolerance induction were associated with the induction of FoxP3 Tregs. We found no difference in the expression of FoxP3 in OVA-specific CD4 ${ }^{+}$lymphocytes after in vitro culture with MLN cells from 1-week-old mice with and without vitamin A supplementation or from 3-week-old mice (Figure 7a). To assess in vivo whether induction of oral tolerance was associated with induction of FoxP3 Tregs, we used a protocol that allowed us to successfully demonstrate the induction of OVA-specific Foxp3 Tregs in mice that received OVA immune complexes in early life. ${ }^{3}$ Neither the time window of OVA administration nor the vitamin A supplementation affected the percentage of Foxp3 positive $\mathrm{T}$ cells (Figure $7 \mathbf{b}$ ). These data are in line with our previous observations showing that Foxp3 Tregs depletion in mice that received soluble OVA through breast milk during whole lactation had no impact of prevention of allergy. ${ }^{4}$ As IFN- $\gamma$ was significantly higher in the lungs of 9-week-old protected mice submitted to a protocol of allergic airway inflammation (Figure 6d), we further assessed whether oral tolerance induction in early life was associated with $\mathrm{T}$ helper type 1 (Th1)-cell differentiation. Both the in vitro and in vivo experiments performed showed that induction of tolerance was associated with IFN- $\gamma$ secretion. Indeed, we found a 2.5 -fold increase in IFN- $\gamma$ secretion when OVA-specific $\mathrm{CD}^{+}$ $\mathrm{T}$ lymphocytes were stimulated in vitro by MLN cells from 1-week-old mice supplemented with Vitamin A or from 3-week-old mice under regular diet compared with secretion observed upon stimulation by MLN cells from 1-week-old mice under regular diet (Figure 7c). IL-10 was not detectable and IL-13 and IL-17 secretion were not affected by the origin of the MLN cells (Supplementary Figure S5). The increased IFN- $\gamma$ secretion was abolished by the addition of LE135 to cell culture demonstrating the necessity of RALDH for this stimulation and was IL-12 dependent as demonstrated by its inhibition following addition of neutralizing anti-IL-12 monoclonal antibody (mAb; Figure 7c). We further analyzed in vivo, whether oral OVA administration induced IFN- $\gamma$-secreting $\mathrm{CD} 4{ }^{+}$lymphocytes in conditions associated with tolerance. We found IFN- $\gamma$-secreting CD4 ${ }^{+} \mathrm{T}$ lymphocytes in MLN of mice that had received OVA during their third week of life or during their first week with vitamin A supplementation but not in mice that did not receive OVA or received it during their first week without vitamin A (Figure 7d). IL-10, IL-17, and IL-5 secretion were not detectable in any of the conditions. As FoxP3 Tregs were recently shown to be a possible source of IFN $-\gamma,{ }^{29,30}$ we analyzed IFN- $\gamma$ production by $\mathrm{CD} 4 \mathrm{~T}$ cells according to their FoxP3 expression. The Figure 7e,f shows that induction of IFN- $\gamma$ in mice that had received OVA during their first week of life with vitamin A supplement or during their third week occurred in FoxP3 ${ }^{-} \mathrm{CD} 4 \mathrm{~T}$ cells but not in $\mathrm{FoxP}^{+}{ }^{+} \mathrm{CD} 4 \mathrm{~T}$ cells. These in vitro and in vivo data strongly suggested that induction of Th1 differentiation in early life by oral OVA administration is required for efficient oral tolerance in adulthood. To confirm this hypothesis, we neutralized IFN- $\gamma$ activity by injection of a neutralizing $\mathrm{mAb} 1$ day before OVA immunization and before the aerosol challenge. Although administration of neutralizing anti-IFN- $\gamma \mathrm{mAb}$ had no impact on allergic airway inflammation in non-protected mice (i.e., mice that received OVA during their first week of life), neutralization of IFN- $\gamma$ abolished allergy prevention induced by oral antigen administration both in vitamin A-supplemented neonates and in 3-week-old mice (Figure $\mathbf{7 g}$ ). These data demonstrate that Th1 differentiation induced in early life is a key factor for effector phase of oral tolerance.

\section{DISCUSSION}

The establishment of oral tolerance is a key immunological mechanism that prevents the development of allergies and other immune-mediated diseases. Here we find that oral tolerance to allergic responses is dependent on a maturation process that becomes efficient only in the third week of life and that depends on the induction of IFN- $\gamma$-secreting $\mathrm{CD} 4{ }^{+} \mathrm{T}$ lymphocytes necessary for tolerance to exert in adulthood (Figure 8). We provide mechanistic data that allow to understand the epidemiological observations indicating that there is an optimal time window of 4-6 months for oral antigen exposure and prevention of allergic disease (reviewed in Prescott et al. ${ }^{12}$ and Muraro et al. ${ }^{13}$ ). We identified that a physiological vitamin A deficiency in neonates was the cause of their inefficient immune regulation. In particular, we found vitamin A deficiency in neonates to be involved in abnormal antigen transfer across immature neonatal gut barrier and in reduced immune response to oral antigens by the neonatal immune system as shown by poor T-cell proliferation and Th1 differentiation both in vitro by neonatal MLN APC and in vivo upon oral OVA administration. We further demonstrated defective immune response to be due to a vitamin A-dependent decreased expression of RALDH in neonatal $\mathrm{CD} 103^{+}$DC. Importantly, supplementation with vitamin A during neonatal period was sufficient to increase neonatal immune responses to responses comparable to those observed in 3-week-old mice 

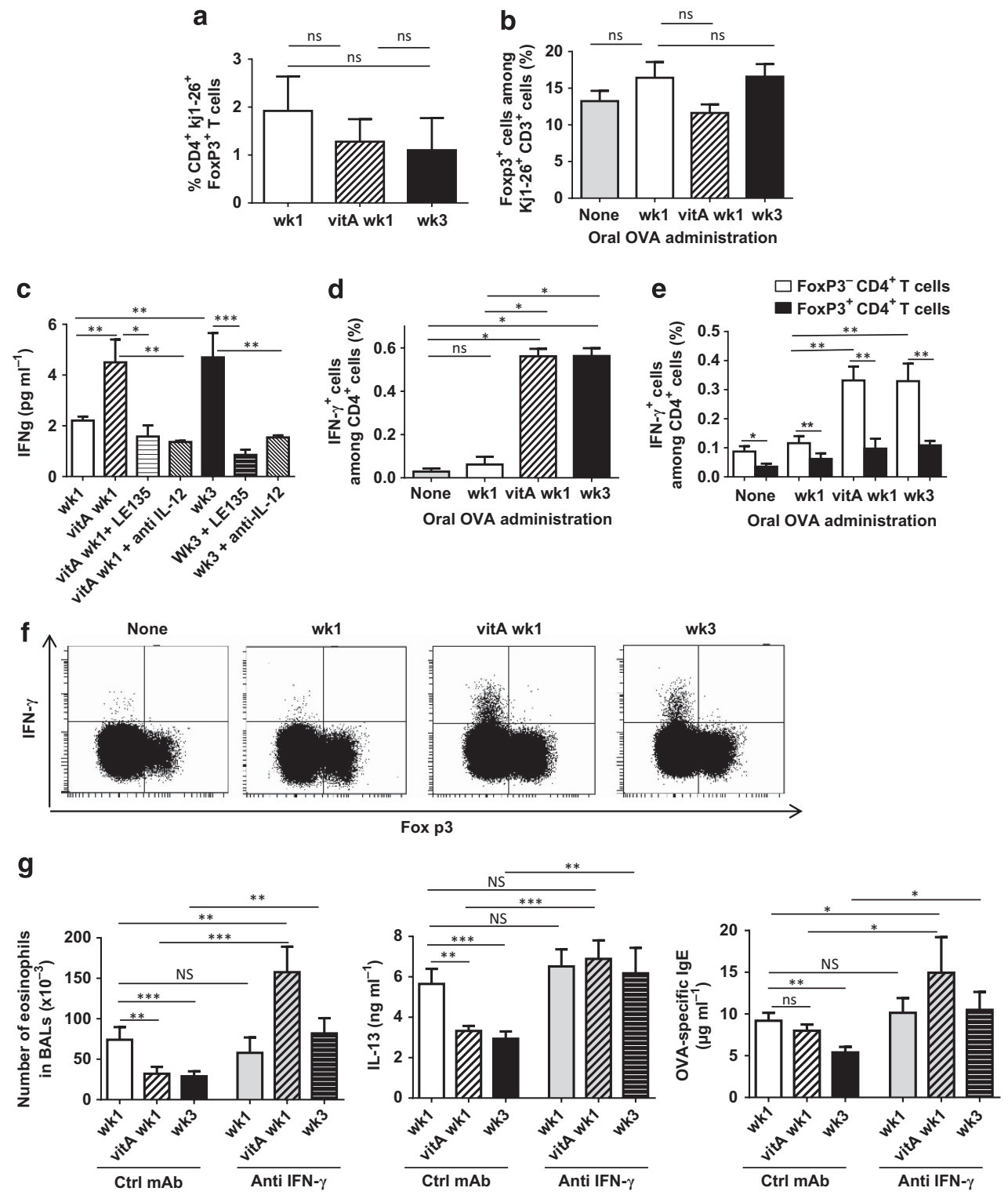

Figure 7 Oral tolerance induced in vitamin A-supplemented neonates and 3-week-old mice is IFN- $\gamma$ dependent. (a, c) MLN cells were cultured during 4 days in the presence of OVA with OVA-specific CFSE-labeled Kj1-26 + CD4 ${ }^{+}$T cells. Where indicated, LE135 RALDH inhibitor or anti-IL-12 neutralizing $\mathrm{mAb}$ antibody was added. Foxp3 expression in CD4 ${ }^{+} \mathrm{kj} 1-26+$ T cells was assessed by flow cytometry analysis (a) and IFN- $\gamma$ secretion were assessed in culture supernatant (c). (b) Percentage of Foxp ${ }^{+}$cells among injected OVA-specific Kj1-26 ${ }^{+} \mathrm{CD} 4^{+} \mathrm{T}$ cells in MLN cells was determined 1 week after last OVA administration. (d-f) Intracellular expression of IFN- $\gamma$ in $\mathrm{CD} 4^{+} \mathrm{T}$ cells from MLN harvested 1 week after last OVA administration, either in total $\mathrm{CD}^{+} \mathrm{T}$ lymphocytes (d) or in Foxp3 ${ }^{+}$and Foxp3 ${ }^{-} \mathrm{CD}^{+}{ }^{+} \mathrm{T}$ cells $(\mathbf{e}, \mathbf{f})$. (g) At 6-8 weeks of age, mice were submitted to OVA immunization and respiratory challenges. IFN- $\gamma$ was neutralized by IP administration of specific mAb before OVA immunization and respiratory challenges or an irrelevant $m A b$ was administered (ctrl mAb). Number of eosinophils in BAL, serum levels of OVA-specific IgE and IL-13 cytokine secretion by lung cells after allergic airway disease induction protocol are represented. Data are expressed as mean \pm s.e.m of five (a, c), two (b, d, g), one (e) independent experiments with $n=6-8$ mice per group in each experiment. ${ }^{\star \star \star} P<0.001 ;{ }^{\star \star} P<0.01 ;{ }^{*} P<0.05$; NS $P>0.05$. BAL, bronchoalveolar lavage; CFSE, carboxyfluorescein succinimidyl ester; IFN- $\gamma$, interferon-gamma; IL, interleukin; IP, immunoprecipitation; mAb, monoclonal antibody; MLN, mesenteric lymph node; NS, not significant; OVA, ovalbumin; wk, weeks.

and allowed efficient induction of oral tolerance and prevention of allergic responses from birth.

The permeability of intestinal epithelium to intact protein is increased in the first week of life both in humans ${ }^{31}$ and in rodents. ${ }^{32,33}$ The gut microbiome has been shown to be dispensable for maturation of gut permeability in early life, ${ }^{32}$ whereas maternal milk was found to be critical for this process but the milk-derived factor involved has so far remained undefined. ${ }^{31,34}$ Here we demonstrate that maternal milk supplementation in vitamin A was sufficient to decrease neonate gut permeability to levels found in 3-week-old mice; this observation further suggests that physiological maturation of neonate gut barrier would involve the known maternal milk supply in vitamin $A^{35,36}$ In view of the existing literature on importance of controlled gut permeability for gut immune homeostasis $^{15,16}$ and of antigen transfer for oral tolerance 


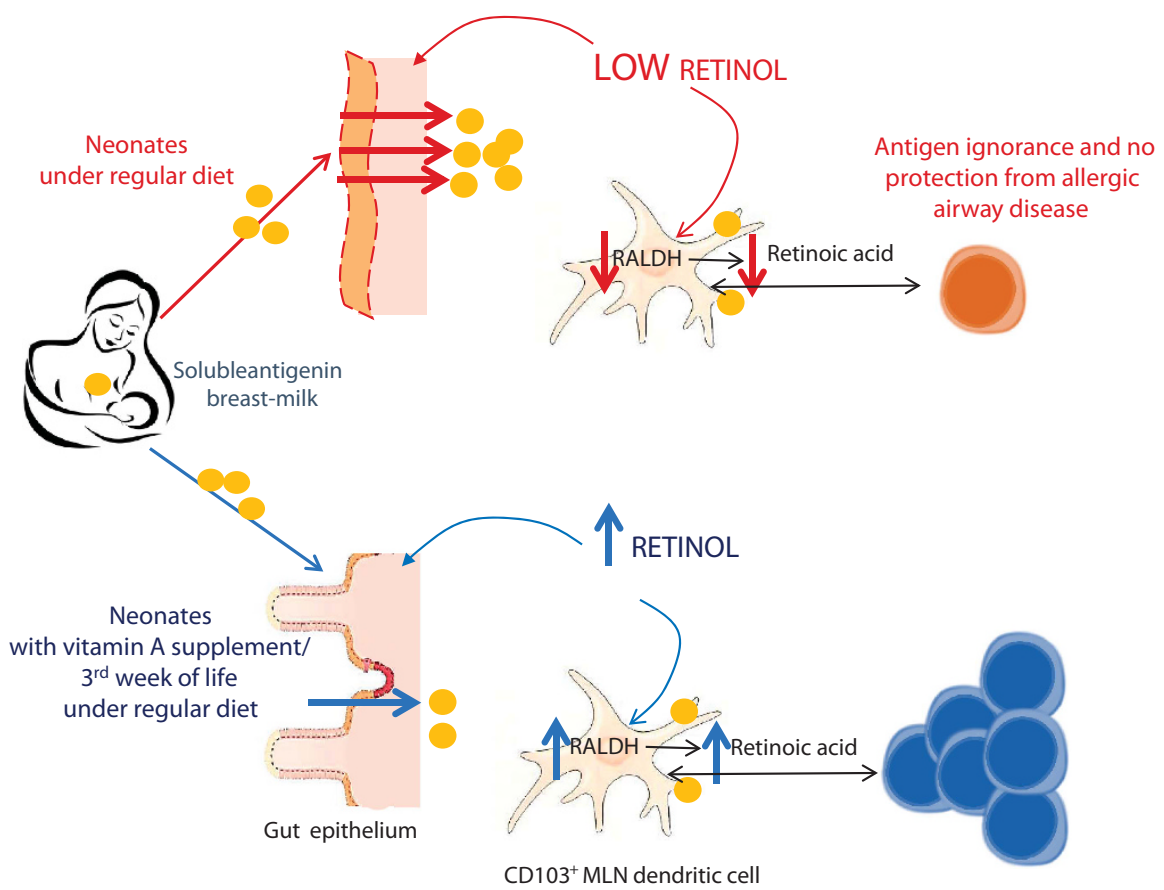

Th1 differentiation and protection from allergic disease

Figure 8 Proposed mechanisms for prevention of allergy by oral tolerance in early life. At birth, neonates are physiologically deficient in Vitamin A (Retinol). This lack is responsible for (1) gut epithelium immaturity characterized by poorly developed crypts and abnormally high antigen transfer (2) inefficient antigen presentation to naïve lymphocytes by MLN CD103 ${ }^{+} \mathrm{DC}$ due to a deficit in RALDH expression and retinoic acid secretion. As a consequence, upon neonatal oral antigen administration, there is no T cell expansion and differentiation and no regulation of allergic response in the long term. Breast milk provides vitamin A to the developing mice and at 3 weeks, retinol levels have reached normal values. Accelerated normalization of retinol levels in the neonates can also be obtained by maternal supplementation in vitamin A. Normalized retinol values are responsible for increased gut barrier, retinoic secretion by MLN CD $103^{+} \mathrm{DC}$ and antigen presentation to naïve lymphocytes. As a consequence, upon oral antigen administration to 3 weeks old mice or to neonates supplemented in vitamin A, T cell expand and differentiate into Th1 lymphocytes which will prevent allergic response in the long term. MLN, mesenteric lymph node.

induction, ${ }^{2,15}$ vitamin A-induced decreased gut permeability most probably contributes to efficiency of oral tolerance induction in vitamin A-supplemented neonates. Importantly for infant nutrition, we found that supplementation of vitamin A did not affect the specialized enzymatic function of neonatal epithelial cells responsible for the digestion of maternal milk.

A low number of antigen-presenting cells have previously been reported and proposed to be responsible for the lack of appropriate immune response in early life. ${ }^{17}$ In contrast, we found that in MLN, the frequency of DC was similar in neonates and at the end of the lactation period. This observation is in agreement with data previously published by Dakic et al. ${ }^{37}$ Recent experiments in adult rodents have demonstrated that $\mathrm{CD}_{103}{ }^{+}$DCs have a key role in intestinal mucosal immune homeostasis (reviewed in Groschwitz et al. ${ }^{18}$ and Adkins et $a l .{ }^{19}$ ). Although the proportion of these cells in 1-week-old neonates was similar to that observed in the 3-week olds, their expression of RALDH was significantly decreased. Only one additional report indicates the specific deficiency of RALDH expression in neonatal $\mathrm{DC}^{21}$ but cause for this defect and consequence on neonatal DC function and neonate susceptibility to oral tolerance had not been assessed. Here we found that low RALDH expression was associated with physiologically low serum retinol level in neonate; importantly, an increase in neonatal serum retinol level by vitamin A supplementation was sufficient to increase RALDH levels in MLN DC from neonates, stimulate T-cell differentiation, and to allow efficient induction of oral tolerance from birth. These observations highlight the critical role of vitamin $\mathrm{A}$ in the regulation of immune homeostasis in early life.

The experiments performed in this work elucidated the mechanisms of oral tolerance induced in early life and demonstrated that the establishment of oral tolerance to allergic responses required induction of Th1 differentiation rather than Foxp3 Tregs as expected from observations on mechanisms of oral tolerance in the adult. ${ }^{2}$ We further found that increased IFN- $\gamma$ secretion by CD4 lymphocytes, by oral tolerance induction in early life, was attributable to lymphocytes that did not expressed Foxp3. Although numerous in vitro data indicate a role of vitamin A in Foxp3 Tregs induction, ${ }^{18,19}$ we found only one publication indicating the necessity for vitamin A for efficient oral tolerance in vivo and this was due to its capacity to induce homing of regulatory $\mathrm{T}$ cells to lamina propria. ${ }^{38}$ Interestingly, it has recently been observed that vitamin $\mathrm{A}$ is also required to stimulate Th1 differentiation 
in vivo in the adult, both in the context of oral antigen administration and infection. ${ }^{39-41}$ The role of IFN- $\gamma$ in oral tolerance in adult has been demonstrated twice ${ }^{42,43}$ and has been subjected to controversy. ${ }^{44,45}$ Our data are supported by reports both in adult mice and humans on protective effects of IFN- $\gamma$ in allergic disease (reviewed in Teixeira et $a l^{46}$ ) but also in autoimmune disease suggesting an important regulatory role of this cytokine (reviewed in Kelchtermans et al. ${ }^{47}$ ). Further experiments will have to determine whether early oral exposure to soluble antigen will also be able to prevent autoimmune disease in a Th1-dependent mechanism. Previous work showed that antigen administration through breast milk can inhibit delayed-type hypersensitivity reaction ${ }^{5}$ suggesting this might be the case.

Reduced IFN- $\gamma$ secretion during early life is a consistent and central finding both in mice and human and following birth there is a progressive increase in the capacity of $\mathrm{CD} 4{ }^{+} \mathrm{T}$ cells to secrete IFN- $\gamma .{ }^{17,48-50}$ Microbial exposure in early life has been proposed to underlie this observation. ${ }^{50}$ Our data strongly suggest that the physiological increase in vitamin A levels in early life is critical for increasing the capacity of Th1 differentiation in response to oral antigen exposure. Indeed, we observed that maturation of immune system capacity to induce Th1 differentiation paralleled the increased in vitamin A levels observed during the first 3 weeks of life. In addition, vitamin A supplementation in neonates was sufficient to allow induction of Th1 cells by oral antigen administration from birth.

The low vitamin A levels in neonatal mice born from mothers on a normal diet are in agreement with previous findings in mice ${ }^{51}$ and, importantly, also in well-nourished humans. Indeed, there are numerous reports of low vitamin A levels in serum and livers of healthy human neonates, infants, and children from countries with vitamin A sufficient diet. ${ }^{35,52-57}$ Infants are born with low body stores of vitamin A regardless of maternal vitamin A status and in well-nourished populations; the ratio of vitamin $\mathrm{A}$ in maternal plasma versus cord blood is 2:1 (ref. 35) due to a strict control of placental transfer of vitamin $\mathrm{A}$, most probably due to the important role of retinol in morphogenesis. Vitamin A supplementation is already advocated for prevention of early life morbidity due to infectious disease in developing countries where supplies of vitamin A in the diet are insufficient. ${ }^{58}$ According to our data, we may also propose vitamin A supplementation in early life to accelerate neonatal gut and immune system maturation and promote the development of oral tolerance from birth.

In conclusion, we have identified that, a micronutrient deficiency specific for the neonatal period conditions the function of the immune system toward the ignorance to oral antigens. We further found that a physiological vitamin A-dependent gut and immune system maturation is necessary for Th1 differentiation upon oral antigen exposure that is a critical in this period of life for long-term oral tolerance. Importantly, the identification of an early life dietary factor that has long-term impact on immune homeostasis will help us to understand early life regulation and mechanisms that may be modulated to prevent the development of immune-mediated diseases, such as allergy.

\section{METHODS}

Mice. Synchronous pregnant BALB/c mice were purchased from Janvier Labs (Le Genest Saint Isle, France) and housed under SPF conditions at "Centre Méditerranéen de Médecine Moléculaire (C3M)". Rag-2 Knockout/Transgenic DO11.10 T Cell Receptor mice were obtained from Fiona Powrie (Oxford, UK). Experiments were performed according to the CIEPAL animal ethics agreement NCE/2012-81.

Mouse model of oral tolerance induction in early life. To assess the ontogeny of oral tolerance, phosphate-buffered saline or OVA (2 mg) were given intragastrically three times a week for lactating mothers during the first, second, or third week after delivery or of during the whole lactation period. ${ }^{4}$ Ova levels in milk were assessed as previously described. ${ }^{4}$ When indicated, neonates were supplemented with vitamin A by maternal administration of a vitamin A-enriched diet (250 IU g ${ }^{-1}$ according to published data, ${ }^{23}$ Safe, France) from 2 days before delivery until the end of the first week. Classical diet contains $7 \mathrm{IU}$ vitamin A per gram (Safe, France). To assess efficiency of oral tolerance induced in early life, 6-8-week-old adult mice were submitted to a protocol of allergic airway inflammation to OVA as previously described. ${ }^{3,4}$ When indicated, mice were injected with $0.5 \mathrm{mg}$ of anti-IFN- $\gamma$ (R4-6A2 clone, ATCC, LGC Standards S.a.r.l., Molsheim, France) or with rat IgG1 (GL113 clone; DNAX, Palo Alto, CA) 1 day before each sensitization and the beginning of challenges. Twenty-four hours after last challenge, mice were killed for the assessment of the severity of allergic airway inflammation by measuring OVA-specific IgE, IgA, and IgG2 aquantification in serum, eosinophils in bronchoalveolar lavage fluids, and lung cell cytokine secretion as previously described.,

Measurement of small intestine permeability. Ussing chambers were used to measure ex vivo gut permeability. Jejunum biopsies from 4-day-old mice breastfed by mothers with control diet or vitamin A-enriched diet and 17-day-old mice breastfed by mothers with control diet were mounted in Ussing Chambers (Transcellab, TBC, Paris, France) with $0.02 \mathrm{~cm}^{2}$ of exposed surface. Both apical and serosal sides of the biopsies were bathed in $3 \mathrm{ml}$ medium (Ham's Nutrient Mixture, HAM's F12 Glutamax; Invitrogen, Saint Aubin, France) and continually oxygenated $\left(95 \% \mathrm{O}_{2}\right.$ and $\left.5 \% \mathrm{CO}_{2}\right)$ at $37^{\circ} \mathrm{C}$ for the duration of the experiment. To measure para-cellular permeability, ${ }^{59}$ after a 10 -min equilibration period, $150 \mu \mathrm{l}$ of media from the apical side of the chamber was taken and replaced with $150 \mu \mathrm{l}$ of fluorescein-5-(and-6)sulfonic acid trisodium salt (molecular weight $=478.32 \mathrm{Da}$, Invitrogen; $\left.1 \mathrm{mg} \mathrm{ml}^{-1}\right)$. Aliquots $(150 \mu \mathrm{l})$ from both apical and serosal sides were taken every $30 \mathrm{~min}$ for $150 \mathrm{~min}$ and fluorescence measured using a spectrophotometer (Tecan Infinite F500, Tecan SA, Lyon, France). Concentrations of fluoresceine $\left(\mathrm{ng} \mathrm{ml}^{-1}\right)$ were obtained by converting fluorescence intensity values using a standard curve. To measure trans-cellular permeability, we used a colorimetric assay based on the oxidation of a substrate (ortho-dianisidine) in the presence of hydrogen peroxide by the enzyme HRP (molecular weight $=45 \mathrm{kDa}$, Sigma). In brief, $60 \mu \mathrm{l}$ of HRP was added to the mucosal side of the tissue and $60 \mu \mathrm{l}$ of medium was added to serosal side and left to equilibrate for $10 \mathrm{~min}$. In a 96-well flat-bottom plate, $60 \mu \mathrm{l}$ of solution from serosal side was collected at baseline (10 min after addition of HRP), at 30, 90, and $150 \mathrm{~min}$. At each time point, $60 \mu \mathrm{l}$ was also taken from the mucosal side to equilibrate the volume in the two chambers. After the last collection point, HRP substrate is freshly prepared by adding $0.3 \% \mathrm{H}_{2} \mathrm{O}_{2}$ and $1 \%$ ortho-dianisidine (Sigma) to the phosphate buffer $(\mathrm{pH}$ 6.0) and immediately, absorbance was measured at $450 \mathrm{~nm}$ using a spectrophotometer at $0,30,60$, and $90 \mathrm{~s}$. Final concentration of transferred HRP (ng ml ${ }^{-1}$ ) was calculated using a standard curve of HRP.

To measure in vivo trans-cellular permeability, we administered $15 \mu \mathrm{g}$ of HRP per gram of mice orally to the pups. Four hours later, 
serum was collected and levels of HRP were assessed by enzyme-linked immunosorbent assay. In brief, serum was added to plates coated with rabbit anti-HRP antibody $\left(10 \mu \mathrm{g} \mathrm{ml}^{-1}\right.$ in phosphate-buffered saline, Sigma); after extensive washing in phosphate-buffered saline-Tween $0.05 \%$, bound HRP was revealed by adding tetramethylbenzidine as substrate; the reaction was stopped with $2 \mathrm{~N} \mathrm{H}_{2} \mathrm{SO}_{4}$ and HRP concentration in sera was determined using a standard curve.

Small intestine histology. Tissue was fixed overnight in $4 \%$ formaldehyde, embedded in paraffin, and sectioned. For immunohistochemistry, the sections were deparaffinized using xylene and rehydrated in a series of ethanol. Endogenous peroxidases were blocked using methanol with $3 \% \mathrm{H}_{2} \mathrm{O}_{2}$.

In vitro T-cell differentiation assay. $\mathrm{CD}^{+}{ }^{+} \mathrm{T}$ lymphocytes were isolated from spleen and lymph nodes single-cell suspensions from adult naive DO11.10 RAG - / - mice using magnetic anti-CD4 beads and LS MACS columns according to the manufacturer's instructions (Miltenyi Biotec, Paris, France). Purity was checked by flow cytometry using CD3 and Kj1-26 mAb (BD, Le Pont de Claix, France) and was always $>95 \%$. CD4 T cells were labeled with $5 \mu \mathrm{m}$ carboxyfluorescein succinimidyl ester. MLN from pups that were 4-5-day old (1 week) or 17-day old carboxyfluorescein succinimidyl ester (3 weeks) were collected and digested with collagenase I (4,000 IU, Gibco, Saint Aubin, France) and DNAse (2,000 IU, Roche, Boulogne Billancourt, France) for $15 \mathrm{~min}$ at $37^{\circ} \mathrm{C}$. CD4 T cells $\left(2.5 \times 10^{5}\right)$ from adult DO11.10 RAG $-/-$ mice were cultured together with $2.5 \times 10^{5}$ of MLN cells, with or without $100 \mu \mathrm{g} \mathrm{ml}^{-1}$ OVA in complete Roswell Park Memorial Institute medium $(10 \%$ fetal calf serum, $2 \mathrm{~mm}$ L-glutamine, $0.05 \mathrm{~mm} 2$-mercaptoethanol, and $100 \mathrm{U}$ of penicillin and streptomycin) for 4 days. When indicated $2 \mu \mathrm{M}$ LE135 (Tocris, Bristol, $\mathrm{UK})$ or neutralizing anti-IL-12 $40 \mathrm{mAb}\left(10 \mu \mathrm{g} \mathrm{ml}^{-1}\right.$, eBioscience, Paris, France) was added to cell cultures. On day 4, cells were stained with anti-CD3 and Kj1-26, permeabilized, and stained for Foxp3 expression (eBioscience). Carboxyfluorescein succinimidyl ester dilution and Foxp3 expression were analyzed by flow cytometry. The supernatants were analyzed for cytokine expression by enzyme-linked immunosorbent assay. IL-5 and IFN- $\gamma$ antibodies were purchased from BD Biosciences (Le Pont de Claix, France) and IL-17 antibodies were purchased from eBiosciences. The lower limit of detection was $300 \mathrm{pg} \mathrm{ml}^{-1}$ for IL-5, $30 \mathrm{pg} \mathrm{ml}^{-1}$ for IFN- $\gamma$, and $10 \mathrm{pg} \mathrm{ml}^{-1}$ for IL-17.

In vivo Th-cell differentiation. One week after last OVA administration through breast milk, MLN cells were collected from pups and cultured with OVA $\left(100 \mu \mathrm{g} \mathrm{ml}^{-1}\right)$ for 3 days. Cells were then restimulated with OVA $\left(100 \mu \mathrm{g} \mathrm{ml}^{-1}\right)$, anti-CD28 $\mathrm{mAb}(\mathrm{BD})$, and Brefeldin A ( $5 \mu \mathrm{M}$, Sigma, Lyon, France) for $5 \mathrm{~h}$. Cells were stained with anti-CD3 and anti-CD4 mAb, fixed, permeabilized using cytofix/ cytoperm reagent (BD), and stained with anti-IL-5, anti-IL-10, anti-IL17 , or anti-IFN- $\gamma$ mAbs (BD). In some experiments, cells were stained with anti-CD3 and anti-CD4 $\mathrm{mAb}$, fixed and permeabilized using reagents for nuclear transcription factor detection (eBioscience), and stained with Foxp3 mAb (eBiocience) and anti-IFN- $\gamma$ mAbs (BD). Cells were analyzed by flow cytometry using a FACS Canto Flow cytometer $(\mathrm{BD})$

In vivo conversion of Foxp3 Tregs. One million Foxp $3^{-} \mathrm{CD} 4^{+} \mathrm{T}$ lymphocytes were purified from splenocytes and lymph node cells from adult naive DO11.10 RAG-2 - / - mice and were injected 1 day before OVA administration. ${ }^{3}$ OVA was given orally to pups as described above. MLNs were harvested 1 week after the last OVA administration and MLN cells were stained for CD3, Kj1.26, and Foxp 3 expression and analyzed by flow cytometry as described above.

Retinol levels in serum. Retinol levels in sera were analyzed by high-performance liquid chromatography using Reagent kit from Chromsystems (Gräfelfing, Germany) in collaboration with Dr Francois Boutboul at Hopital Pasteur (Nice, France).
Dendritic cell phenotype. MLN single-cell suspensions from pups aged $4-5$ or 17 days were stained with anti-CD11c, anti-MHCII, antiF4/80, anti-CD11b, and anti-CD103 mAbs (all from BD and eBiosciences). Macrophages were excluded from the analysis according to their expression of F4/80. Double staining of MHCII and $\mathrm{CD} 11 \mathrm{c}$ defined DC population that was further sub-divided by CD103 expression (Figure 3d). CD103 ${ }^{+}$DCs were analyzed for their RALDH enzyme activity using Stem cell protocol and reagents (Stem cell, Grenoble, France). A specific inhibitor of RALDH, diethylaminobenzaldehyde, was used to control for background fluorescence. DCs were also analyzed for their surface expression of co-stimulatory and inhibitory molecules CD80, CD86, PDL-2, and PDL-1 (all from BD and eBiosciences).

In vitro and in vivo OVA uptake. In vitro: MLN cells $\left(1 \times 10^{6}\right)$ were incubated with $10 \mu \mathrm{g} \mathrm{ml}^{-1}$ of OVA-alexa 488 (Life Technologies Saint Aubin, France) during $40 \mathrm{~min}$ at $37^{\circ} \mathrm{C}$. The percentage of CD11c ${ }^{+}$ $\mathrm{MHCII}^{+} \mathrm{CD} 03^{+} \mathrm{OVA}^{+}$DCs was assessed by flow cytometry. Culture without OVA was performed to determine fluorescence specific for OVA uptake and background fluorescence of cells pulsed at $0{ }^{\circ} \mathrm{C}$ was subtracted.

In vivo: A amount of $30 \mu \mathrm{g}$ of OVA-alexa 488 per gram of mice was administered orally to mice. At $18 \mathrm{~h}$ later, MLN cells were collected and the percentage of $\mathrm{CD}_{11 \mathrm{c}^{+}} \mathrm{MHCII}^{+} \mathrm{CD} 03^{+} \mathrm{OVA}^{+} \mathrm{DCs}$ was assessed by flow cytometry.

Statistical analysis. Statistical significance was assessed using a twotailed $P$ value calculated with Mann-Whitney non-parametric test using GraphPad Prism software (La Jolla, CA). ${ }^{* *} P<0.001$; ${ }^{\star *} P<0.01 ;{ }^{\star} P<0.05$; NS $P>0.05$.

SUPPLEMENTARY MATERIAL is linked to the online version of the paper at http://www.nature.com/mi

\section{ACKNOWLEDGMENTS}

We thank Dr Francois Boutboul and his team from Hopital Pasteur de Nice Biochemistry Department for measurement of serum vitamin A levels, Fabienne Anjuere and Frédéric Larbret for the help in DC phenotype analysis, Véronique Corcelle and the animal facility staff for their excellent care of mice, and Francis Hautem for excellent laboratory management. This work was supported by the Institut National de la Santé et Recherche Médicale, Université de Nice Sophia-Antipolis, Fondation Princesse Grace, Agence Nationale de la Recherche, and Fondation de recherche en santé respiratoire.

\section{AUTHOR CONTRIBUTIONS}

M.T. and A.R. performed experiments on immune mechanisms of immune tolerance; P.M. set up experiments on ontogeny of oral tolerance and phenotyping neonatal DC; M.T. analyzed data of experiments on immune mechanisms of immune tolerance; L.B. and M.K.T. performed and analyzed experiments on gut permeability; V.D.M. and G.R.vdB. performed histologic analysis of gut maturation; M.T., M.K.T., and V.V. discussed interpretation and implication of the data; M.T. and V.V. wrote the paper; V.V. designed and supervised the whole project. All authors read, commented on the manuscript, and approved the final version.

\section{DISCLOSURE}

The authors declare no conflict of interest.

c 2016 Society for Mucosal Immunology

\section{REFERENCES}

1. Faria, A.M. \& Weiner, H.L. Oral tolerance. Immunol. Rev. 206, 232-259 (2005).

2. Pabst, O. \& Mowat, A.M. Oral tolerance to food protein. Mucosal Immunol. 5, 232-239 (2012). 
3. Mosconi, E. et al. Breast milk immune complexes are potent inducers of oral tolerance in neonates and prevent asthma development. Mucosal Immunol. 3, 461-474 (2010).

4. Verhasselt, $\mathrm{V}$. et al. Breast milk-mediated transfer of an antigen induces tolerance and protection from allergic asthma. Nat. Med. 14, 170-175 (2008).

5. Strobel, S. Immunity induced after a feed of antigen during early life: oral tolerance v. sensitisation. Proc. Nutr. Soc. 60, 437-442 (2001).

6. Strobel, S. Neonatal oral tolerance. Ann. NY Acad. Sci. 778, 88-102 (1996).

7. Strobel, S. \& Ferguson, A. Immune responses to fed protein antigens in mice. 3. Systemic tolerance or priming is related to age at which antigen is first encountered. Pediatr. Res. 18, 588-594 (1984).

8. Hanson, D.G. Ontogeny of orally induced tolerance to soluble proteins in mice. I. Priming and tolerance in newborns. J. Immunol. 127, 1518-1524 (1981).

9. Miller, A., Lider, O., Abramsky, O. \& Weiner, H.L. Orally administered myelin basic protein in neonates primes for immune responses and enhances experimental autoimmune encephalomyelitis in adult animals. Eur. J. Immunol. 24, 1026-1032 (1994).

10. Wahn, U. \& von Mutius, E. Childhood risk factors for atopy and the importance of early intervention. J. Allergy Clin. Immunol. 107, 567-574 (2001).

11. Karlsson, M.R., Rugtveit, J. \& Brandtzaeg, P. Allergen-responsive CD4 ${ }^{+}$ CD25 + regulatory Tcells in children who have outgrown cow's milk allergy. J. Exp. Med. 199, 1679-1688 (2004).

12. Prescott, S.L. et al. The importance of early complementary feeding in the development of oral tolerance: concerns and controversies. Pediatr. Allergy Immunol. 19, 375-380 (2008).

13. Muraro, A. et al. EAACl food allergy and anaphylaxis guidelines. Primary prevention of food allergy. Allergy 69, 590-601 (2014).

14. Prescott, S.L. Early-life environmental determinants of allergic diseases and the wider pandemic of inflammatory noncommunicable diseases. J. Allergy Clin. Immunol. 131, 23-30 (2013).

15. Menard, S., Cerf-Bensussan, N. \& Heyman, M. Multiple facets of intestinal permeability and epithelial handling of dietary antigens. Mucosal Immunol. 3, 247-259 (2010).

16. Groschwitz, K.R. \& Hogan, S.P. Intestinal barrier function: molecular regulation and disease pathogenesis. J. Allergy Clin. Immunol. 124, 3-20 (2009).

17. Adkins, B., Leclerc, C. \& Marshall-Clarke, S. Neonatal adaptive immunity comes of age. Nat. Rev. Immunol. 4, 553-564 (2004).

18. Agace, W.W. \& Persson, E.K. How vitamin A metabolizing dendritic cells are generated in the gut mucosa. Trends Immunol. 33, 42-48 (2012).

19. Hall, J.A., Grainger, J.R., Spencer, S.P. \& Belkaid, Y. The role of retinoic acid in tolerance and immunity. Immunity 35, 13-22 (2011).

20. Ross, A.C. Diet in vitamin Aresearch. Methods Mol. Biol. 652, 295-313 (2010).

21. Molenaar, R. et al. Expression of retinaldehyde dehydrogenase enzymes in mucosal dendritic cells and gut-draining lymph node stromal cells is controlled by dietary vitamin A. J. Immunol. 186, 1934-1942 (2011).

22. Villablanca, E.J. et al. MyD88 and retinoic acid signaling pathways interact to modulate gastrointestinal activities of dendritic cells. Gastroenterology 141, 176-185 (2011).

23. Schuster, G.U., Kenyon, N.J. \& Stephensen, C.B. Vitamin A deficiency decreases and high dietary vitamin $A$ increases disease severity in the mouse model of asthma. J. Immunol. 180, 1834-1842 (2008).

24. Geissmann, F. et al. Retinoids regulate survival and antigen presentation by immature dendritic cells. J. Exp. Med. 198, 623-634 (2003).

25. Sallusto, F., Cella, M., Danieli, C. \& Lanzavecchia, A. Dendritic cells use macropinocytosis and the mannose receptor to concentrate macromolecules in the major histocompatibility complex class II compartment: downregulation by cytokines and bacterial products. J. Exp. Med. 182, 389-400 (1995).

26. McCullough, F.S., Northrop-Clewes, C.A. \& Thurnham, D.I. The effect of vitamin A on epithelial integrity. Proc. Nutr. Soc. 58, 289-293 (1999).

27. Muncan, $\mathrm{V}$. et al. Blimp1 regulates the transition of neonatal to adult intestinal epithelium. Nat. Commun. 2, 452 (2011).

28. Harper, J., Mould, A., Andrews, R.M., Bikoff, E.K. \& Robertson, E.J. The transcriptional repressor Blimp1/Prdm1 regulates postnatal reprogramming of intestinal enterocytes. Proc. Natl Acad. Sci. USA 108, 1058510590 (2011).
29. Esposito, M. et al. IL-17- and IFN-gamma-secreting Foxp3 + T cells infiltrate the target tissue in experimental autoimmunity. J. Immunol. 185, 7467-7473 (2010).

30. Dominguez-Villar, M., Baecher-Allan, C.M. \& Hafler, D.A. Identification of T helper type 1-like, Foxp3 + regulatory $\mathrm{T}$ cells in human autoimmune disease. Nat. Med. 17, 673-675 (2011).

31. Catassi, C., Bonucci, A., Coppa, G.V., Carlucci, A. \& Giorgi, P.L. Intestinal permeability changes during the first month: effect of natural versus artificial feeding. J. Pediatr. Gastroenterol. Nutr. 21, 383-386 (1995).

32. Heyman, M., Crain-Denoyelle, A.M., Corthier, G., Morgat, J.L. \& Desjeux, J.F. Postnatal development of protein absorption in conventional and germ-free mice. Am. J. Physiol. 251 (3 Pt 1), G326-G331 (1986).

33. Udall, J.N., Pang, K., Fritze, L., Kleinman, R. \& Walker, W.A. Development of gastrointestinal mucosal barrier. I. The effect of age on intestinal permeability to macromolecules. Pediatr. Res. 15, 241-244 (1981).

34. Udall, J.N. et al. Development of gastrointestinal mucosal barrier. II. The effect of natural versus artificial feeding on intestinal permeability to macromolecules. Pediatr. Res. 15, 245-249 (1981).

35. Haskell, M.J. \& Brown, K.H. Maternal vitamin A nutriture and the vitamin A content of human milk. J. Mammary Gland. Biol. Neoplasia 4, 243-257 (1999).

36. Chappell, J.E., Francis, T. \& Clandinin, M.T. Vitamin A and E content of human milk at early stages of lactation. Early Hum. Dev. 11, 157-167 (1985).

37. Dakic, A. et al. Development of the dendritic cell system during mouse ontogeny. J. Immunol. 172, 1018-1027 (2004).

38. Cassani, B. et al. Gut-tropic T cells that express integrin alpha4beta7 and CCR9 are required for induction of oral immune tolerance in mice. Gastroenterology 141, 2109-2118 (2011).

39. DePaolo, R.W. et al. Co-adjuvant effects of retinoic acid and IL-15 induce inflammatory immunity to dietary antigens. Nature 471, 220-224 (2011).

40. Hall, J.A. et al. Essential role for retinoic acid in the promotion of $4^{(+)}$Tcell effector responses via retinoic acid receptor alpha. Immunity 34, 435-447 (2011).

41. Brown, C.C. et al. Retinoic Acid is essential for Th1 cell lineage stability and prevents transition to a th17 cell program. Immunity 42, 499-511 (2015).

42. Kweon, M.N. et al. Lack of orally induced systemic unresponsiveness in IFN-gamma knockout mice. J. Immunol. 160, 1687-1693 (1998).

43. Lee, H.O., Miller, S.D., Hurst, S.D., Tan, L.J., Cooper, C.J. \& Barrett, T.A. Interferon gamma induction during oral tolerance reduces T-cell migration to sites of inflammation. Gastroenterology 119, 129-138 (2000).

44. Mowat, A.M., Steel, M., Leishman, A.J. \& Garside, P. Normal induction of oral tolerance in the absence of a functional IL-12-dependent IFN-gamma signaling pathway. J. Immunol. 163, 4728-4736 (1999).

45. Kjerrulf, M., Grdic, D., Ekman, L., Schon, K., Vajdy, M. \& Lycke, N.Y. Interferon-gamma receptor-deficient mice exhibit impaired gut mucosal immune responses but intact oral tolerance. Immunology 92, 60-68 (1997).

46. Teixeira, L.K., Fonseca, B.P., Barboza, B.A. \& Viola, J.P. The role of interferon-gamma on immune and allergic responses. Mem. Inst. Oswaldo Cruz 100 (Suppl 1), 137-144 (2005).

47. Kelchtermans, H., Billiau, A. \& Matthys, P. How interferon-gamma keeps autoimmune diseases in check. Trends Immunol. 29, 479-486 (2008).

48. Holt, P.G., Upham, J.W. \& Sly, P.D. Contemporaneous maturation of immunologic and respiratory functions during early childhood: implications for development of asthma prevention strategies. J. Allergy Clin. Immunol. 116, 16-24 (2005).

49. Tulic, M.K. et al. Differences in innate immune function between allergic and nonallergic children: new insights into immune ontogeny. J. Allergy Clin. Immunol. 127, 470-478 (2011).

50. Vuillermin, P.J. et al. Microbial exposure, interferon gamma gene demethylation in naive T-cells, and the risk of allergic disease. Allergy 64, 348-353 (2009).

51. Garcia, A.L., Ruhl, R. \& Schweigert, F.J. Retinoid concentrations in the mouse during postnatal development and after maternal vitamin A supplementation. Ann. Nutr. Metab. 49, 333-341 (2005).

52. Olson, J.A., Gunning, D.B. \& Tilton, R.A. Liver concentrations of vitamin A and carotenoids, as a function of age and other parameters, of 
American children who died of various causes. Am. J. Clin. Nutr. 39, 903910 (1984).

53. Malvy, D.J., Burtschy, B., Dostalova, L. \& Amedee-Manesme, O. Serum retinol, beta-carotene, alpha-tocopherol and cholesterol in healthy French children. Int. J. Epidemiol. 22, 237-246 (1993).

54. Delvin, E.E., Salle, B.L., Reygrobellet, B., Mellier, G. \& Claris, O. Vitamin A and E supplementation in breast-fed newborns. J. Pediatric Gastroenterol. Nutr. 31, 562-565 (2000).

55. Shenai, J.P., Chytil, F., Jhaveri, A. \& Stahlman, M.T. Plasma vitamin A and retinol-binding protein in premature and term neonates. J. Pediatr. 99, 302-305 (1981).
56. Mitchell, G.V., Young, M. \& Seward, C.R. Vitamin A and carotene levels of a selected population in metropolitan Washington, D. C. Am. J. Clin. Nutr. 26, 992-997 (1973).

57. Pesonen, M., Kallio, M.J., Siimes, M.A. \& Ranki, A. Retinol concentrations after birth are inversely associated with atopic manifestations in children and young adults. Clin. Exp. Allergy 37, 54-61 (2007).

58. Stephensen, C.B. Vitamin A, infection, and immune function. Ann. Rev. Nutr. 21, 167-192 (2001).

59. Piche, T. et al. Impaired intestinal barrier integrity in the colon of patients with irritable bowel syndrome: involvement of soluble mediators. Gut 58, 196-201 (2009). 